\title{
Measurement of the Variations in Thickness and Refractive Index of NIF Crystals
}

Gary E. Sommargren, Donald W. Phillion, Michael A. Johnson, Lloyd S. Bradsher

January 29, 2002 


\section{DISCLAIMER}

This document was prepared as an account of work sponsored by an agency of the United States Government. Neither the United States Government nor the University of California nor any of their employees, makes any warranty, express or implied, or assumes any legal liability or responsibility for the accuracy, completeness, or usefulness of any information, apparatus, product, or process disclosed, or represents that its use would not infringe privately owned rights. Reference herein to any specific commercial product, process, or service by trade name, trademark, manufacturer, or otherwise, does not necessarily constitute or imply its endorsement, recommendation, or favoring by the United States Government or the University of California. The views and opinions of authors expressed herein do not necessarily state or reflect those of the United States Government or the University of California, and shall not be used for advertising or product endorsement purposes.

This work was performed under the auspices of the U. S. Department of Energy by the University of California, Lawrence Livermore National Laboratory under Contract No. W-7405-Eng-48.

This report has been reproduced

directly from the best available copy.

Available to DOE and DOE contractors from the

Office of Scientific and Technical Information

P.O. Box 62, Oak Ridge, TN 37831

Prices available from (423) 576-8401

http://apollo.osti.gov/bridge/

Available to the public from the

National Technical Information Service

U.S. Department of Commerce

5285 Port Royal Rd.,

Springfield, VA 22161

http://www.ntis.gov/

\section{OR}

Lawrence Livermore National Laboratory

Technical Information Department's Digital Library

http://www.Ilnl.gov/tid/Library.html 


\title{
Measurement of the variations in thickness and refractive index of NIF crystals
}

\author{
Gary E. Sommargren, Donald W. Phillion, \\ Michael A. Johnson, Lloyd S. Bradsher
}

\section{Introduction}

This report discusses one method of characterizing the variations in the physical thickness and refractive index of NIF doubler, tripler and switch crystals that are relatively thin $(\sim 10 \mathrm{~mm}$ thick). These particular measurements are difficult to perform with standard laser interferometers when the front and back substrate surfaces are near-parallel. A complicated interference pattern is formed from the interference of more than two beams due to the temporal coherence of the laser source. There are a number of methods that can be used to minimize this problem. They are referenced in a paper by Peter de Groot ${ }^{1}$. In this report we discuss a method that eliminates the problem completely and show the results of measurements of two crystals.

\section{Measurement approach}

Figure 1 shows a typical interferometric setup for measuring thin crystals. Note there are four reflected beams from the surfaces within the interferometer cavity.

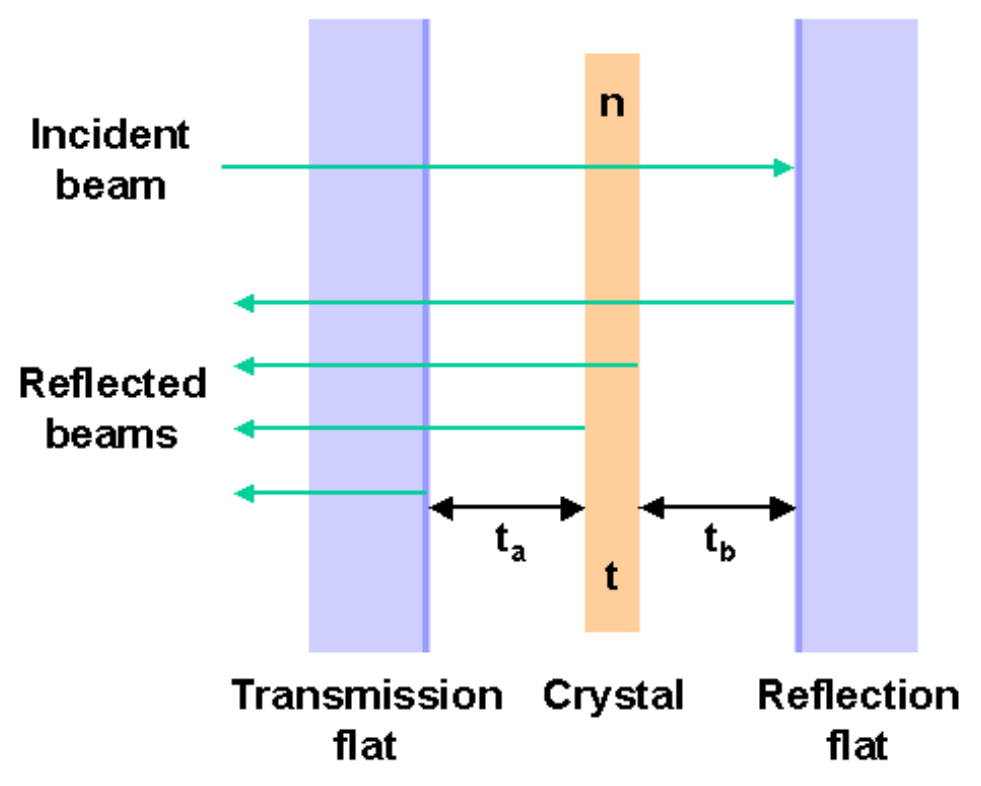

Fig. 1. Typical interferometric setup for measuring a crystal. 
Pairs of these reflected beams contain information about the optical path differences (OPDs) between surfaces. From this information variations in the crystal thickness and refractive index can be calculated. The phase shifting diffraction interferometer ${ }^{2}$ (PSDI) developed for the EUVL Program has two distinct properties that eliminate the multiple beam interference and permit selective interference between only the two beams of interest: (1) a short coherence length; (2) the ability to adjust the time delay between the interfering beams so that only the pair of interest are temporally coherent.

Three measurements are necessary to determine the variations in the physical thickness and refractive index of a crystal. The interferometric measurements are shown in Fig. 2.

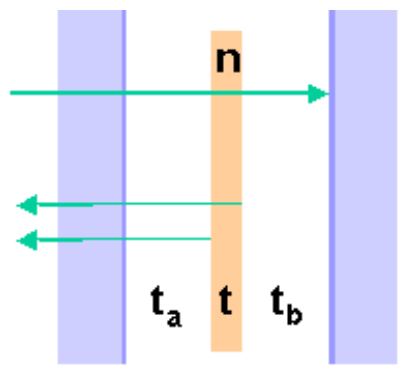

\author{
Measurement 1 : crystal only
}

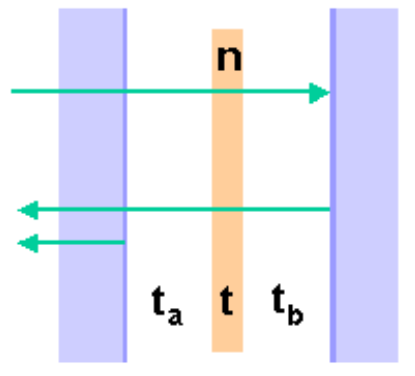

Measurement 2: crystal and cavity

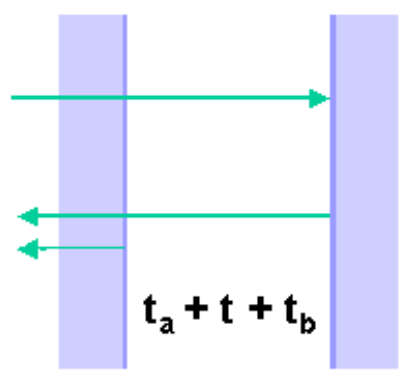

Measurement 3: cavity only

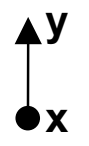

Fig. 2. The three measurements required to characterize the variation in the thickness and refractive index of a NIF crystal. 


\section{Equations}

The OPDs for the three measurements are:

$$
\begin{aligned}
& \mathrm{OPD}_{1}(x, y)=2(n(x, y) t(x, y))=M_{1}(x, y)+m_{1} \lambda \\
& \operatorname{OPD}_{2}(x, y)=2\left(t_{a}+n(x, y) t(x, y)+t_{b}\right)=M_{2}(x, y)+m_{2} \lambda
\end{aligned}
$$

and

$$
\mathrm{OPD}_{3}(x, y)=2\left(t_{a}+t(x, y)+t_{b}\right)=M_{3}(x, y)+m_{3} \lambda .
$$

Since an interferometer measures OPD modulo $\lambda$, the actual interferometer measurement $\mathbf{M}_{\mathbf{i}}$ (units of length) is the departure from a nominal OPD $\left(\mathbf{m}_{\mathbf{i}} \lambda\right)$. Note that $\mathbf{O P D _ { i }}, \mathbf{M}_{\mathbf{i}}, \mathbf{t}$ and $\mathbf{n}$ are functions of the transverse spatial coordinates $(\mathbf{x}, \mathbf{y})$ whereas $\mathbf{m}_{\mathbf{i}}$ is not. This dependence will be dropped in the notation to simplify the equations. Also note that by taking data in the order shown in Fig.2 the interferometer is in no way disturbed during the measurement sequence, thus avoiding errors caused by unintentional misalignment.

Combining the three equations gives,

$$
t=\left[\left(M_{1}-M_{2}+M_{3}\right) / 2\right]+\left[\left(m_{1}-m_{2}+m_{3}\right) \lambda / 2\right]=t_{0}+\Delta t,
$$

where $t_{0} \equiv\left(m_{1}-m_{2}+m_{3}\right) \lambda / 2$ is the nominal thickness of the crystal and the variation in the crystal thickness is given by,

$$
\Delta t=\left(M_{1}-M_{2}+M_{3}\right) / 2 .
$$

Note: $\Delta t$ includes the absolute wedge in the crystal, a quantity often lost in other interferometric measurements. It is also independent of the surface figure of the transmission and reflection flats.

The variation in crystal refractive index is found using the first equation. Rewriting it in terms of $\mathbf{t}=\mathbf{t}_{0}+\Delta t$ and $\mathbf{n}=\mathbf{n}_{0}+\Delta \mathbf{n}$, where $\mathbf{n}_{0}$ is the nominal refractive index (independent of $(\mathbf{x}, \mathbf{y})$ ) and $\Delta \mathbf{n}$ is the spatial variation in refractive index, gives,

$$
2\left(n_{0}+\Delta n\right)\left(t_{0}+\Delta t\right)=M_{1}+m_{1} \lambda
$$

or

$$
2\left[n_{0} t_{0}+n_{0} \Delta t+t_{0} \Delta n+\Delta n \Delta t\right]=M_{1}+m_{1} \lambda .
$$


The term $\Delta \mathbf{n} \Delta \mathrm{t}$ is small and can be dropped, and $2 \mathbf{n}_{0} \mathbf{t}_{0} \equiv \mathbf{m}_{1} \lambda$, reducing the equation to,

$$
2\left[n_{0} \Delta t+t_{0} \Delta n\right]=M_{1} .
$$

Solving for $\Delta \mathbf{n}$ gives,

$$
\Delta \mathrm{n}=\left[\mathrm{M}_{1} / 2-\mathrm{n}_{0} \Delta t\right] / \mathrm{t}_{0} .
$$

Substituting for $\Delta \mathbf{t}$ gives the expression for the variation in the index of refraction of the crystal as,

$$
\Delta \mathrm{n}=\left[\left(1-\mathrm{n}_{0}\right) M_{1}+\mathrm{n}_{0}\left(M_{2}-M_{3}\right)\right] /\left(2 \mathrm{t}_{0}\right) .
$$

Note: The laser wavelength used to make these measurements is $532 \mathrm{~nm}$, which is $2 \omega$. The actual $\Delta \mathbf{n}$ for $\omega$ and $3 \omega$ must be calculated from the known dispersion.

\section{The interferometer (PSDI)}

The measurement section of the PSDI is shown in Fig. 3 where both the reference and measurements beams are introduced by a single mode optical

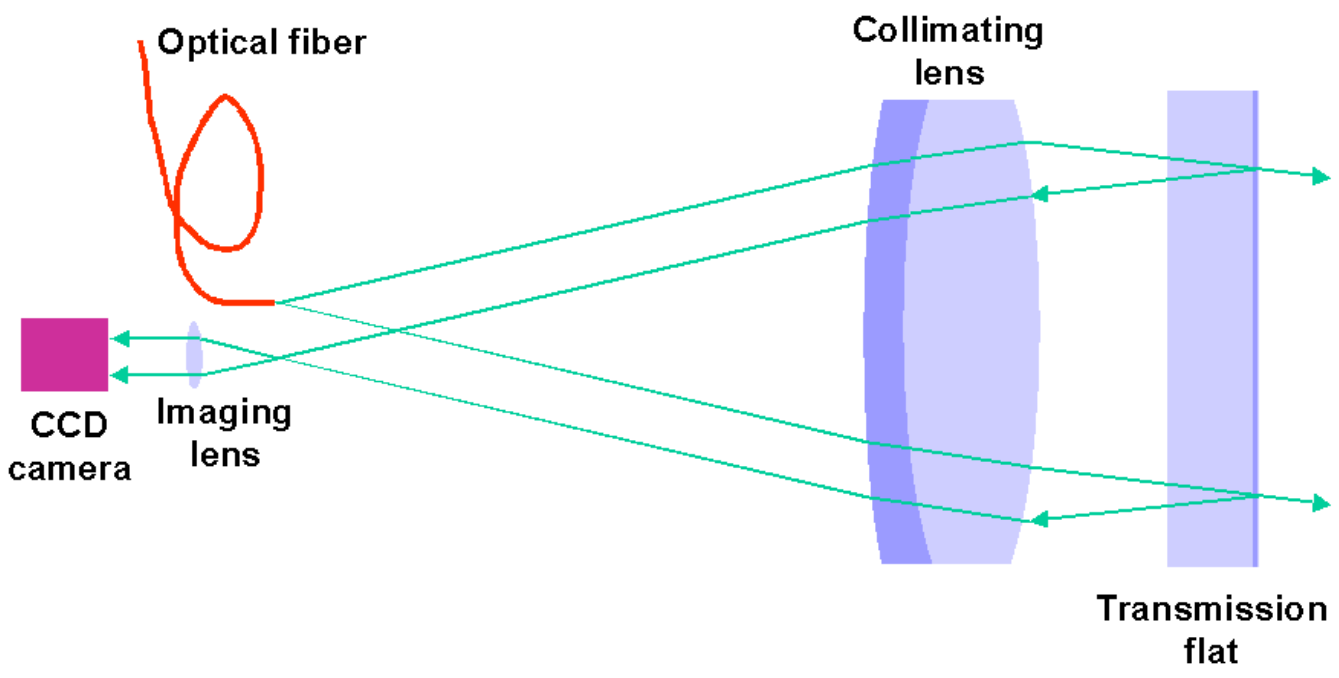

Fig. 3. Measurement section of the PSDI. 
fiber. The beams returning from the interferometer flats and crystal are brought to focus in close proximity $(\sim 0.5 \mathrm{~mm})$ to the fiber where they pass through a lens that images the crystal onto the CCD.

The complete PSDI, containing the short coherence length $(\sim 2 \mathrm{~mm})$ laser, PZT phase shifter and delay line, is shown in Fig. 4.

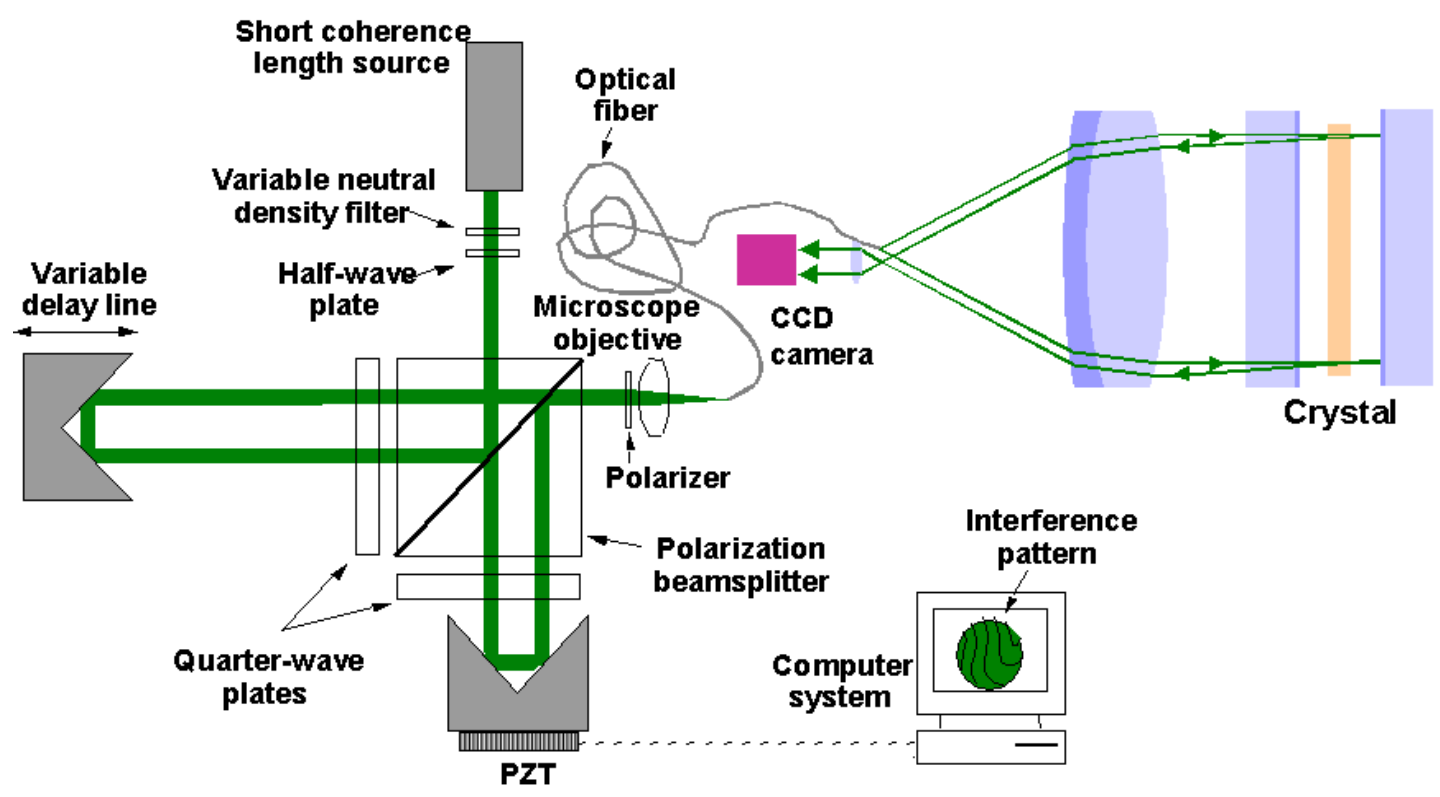

Fig. 4. Complete PSDI for characterization of NIF crystals.

\section{Measurement sensitivity}

What accuracy can we expect for $\Delta \mathbf{t}$ and $\Delta \mathbf{n}$ ? Using standard error propagation methods, where $\Delta \mathbf{t}$ and $\Delta \mathbf{n}$ are functions of the spatially varying measurements $\mathbf{M}_{1}, \mathbf{M}_{\mathbf{2}}$ and $\mathbf{M}_{3}$, the errors in $\Delta \mathbf{t}$ and $\Delta \mathbf{n}$ are given by,

$$
\delta(\Delta t)=\left[\Sigma_{i}\left(\left(\partial \Delta t / \partial M_{i}\right) \delta M_{i}\right)^{2}\right]^{1 / 2},
$$

and

$$
\delta(\Delta \mathbf{n})=\left[\Sigma_{\mathrm{i}}\left(\left(\partial \Delta \mathrm{n} / \partial \mathbf{M}_{\mathrm{i}}\right) \delta \mathbf{M}_{\mathrm{i}}\right)^{2}\right]^{1 / 2},
$$

where $\mathbf{i}=\mathbf{1 , 2}$ and 3 . 
The partial derivatives of $\Delta \mathbf{t}$ and $\Delta \mathbf{n}$ are:

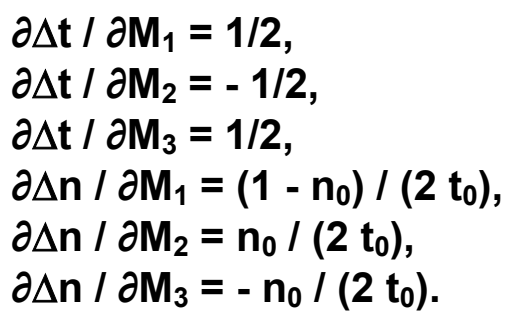

For the crystals that were measured, the nominal values of the parameters are:

$$
\begin{aligned}
& t_{0}=10 \mathrm{~mm}, \\
& n_{0}=1.51, \\
& \delta M_{1}=\delta M_{2}=\delta M_{3}=0.5 n m ~ r m s
\end{aligned}
$$

Table 1 summarizes the individual and total errors:

\begin{tabular}{|l|l|l|}
\hline \multicolumn{1}{|c|}{ Error source $\left(\mathrm{M}_{\mathrm{i}}\right)$} & \multicolumn{1}{c|}{$\left(\partial \Delta \mathrm{t} / \partial \mathrm{M}_{\mathrm{i}}\right) \delta \mathrm{M}_{\mathrm{i}}$} & \multicolumn{1}{c|}{$\left(\partial \Delta \mathrm{n} / \partial \mathrm{M}_{\mathrm{i}}\right) \delta \mathrm{M}_{\mathrm{i}}$} \\
\hline $\mathrm{M}_{1}$ & $0.25 \mathrm{~nm} \mathrm{rms}$ & $-1.28 \times 10^{-8} \mathrm{rms}$ \\
\hline $\mathrm{M}_{2}$ & $-0.25 \mathrm{~nm} \mathrm{rms}$ & $3.75 \times 10^{-8} \mathrm{rms}$ \\
\hline $\mathrm{M}_{3}$ & $0.25 \mathrm{~nm} \mathrm{rms}$ & $-3.75 \times 10^{-8} \mathrm{rms}$ \\
\hline & & \\
\hline Total rss error & $\delta(\Delta \mathrm{t})=0.43 \mathrm{~nm} \mathrm{rms}$ & $\delta(\Delta \mathrm{n})=5.45 \times 10^{-8} \mathrm{rms}$ \\
\hline
\end{tabular}

Table 1. The error contributions and total root-sum-squared (rss) error for $\Delta \mathrm{t}$ and $\Delta \mathrm{n}$.

\section{Crystal measurements}

Two crystals were measured and analyzed using the interferometer and procedures described above. Each crystal was a $150 \mathrm{~mm}$ square sample, $10 \mathrm{~mm}$ thick. One was a switch crystal, designated on an edge as "RG9B $0^{\circ} Z$ ", and the other was a tripler crystal designated "227-11". The crystals are shown in Fig.5. Each crystal was measured with both horizontal and vertical polarization referenced to the edge marking (vertical polarization was parallel to the marked edge). Each edge was also marked with an arrow pointing toward a crystal face. The crystal was oriented with the incoming laser light entering that face.

The circular aperture of the interferometer was $130 \mathrm{~mm}$ in diameter. Measurements were taken with this aperture centered on the crystals. Each of the three measurements, $\mathbf{M}_{1}, \mathbf{M}_{\mathbf{2}}$ and $\mathbf{M}_{3}$, was an average of 25 data sets. No spatial smoothing was done on the raw data. The spatial sampling of the crystals by the CCD camera was $150 \mu \mathrm{m} / \mathrm{pixel}(6.7 \mathrm{samples} / \mathrm{mm})$. Spatial resolution was limited by the CCD, not the imaging lens. 


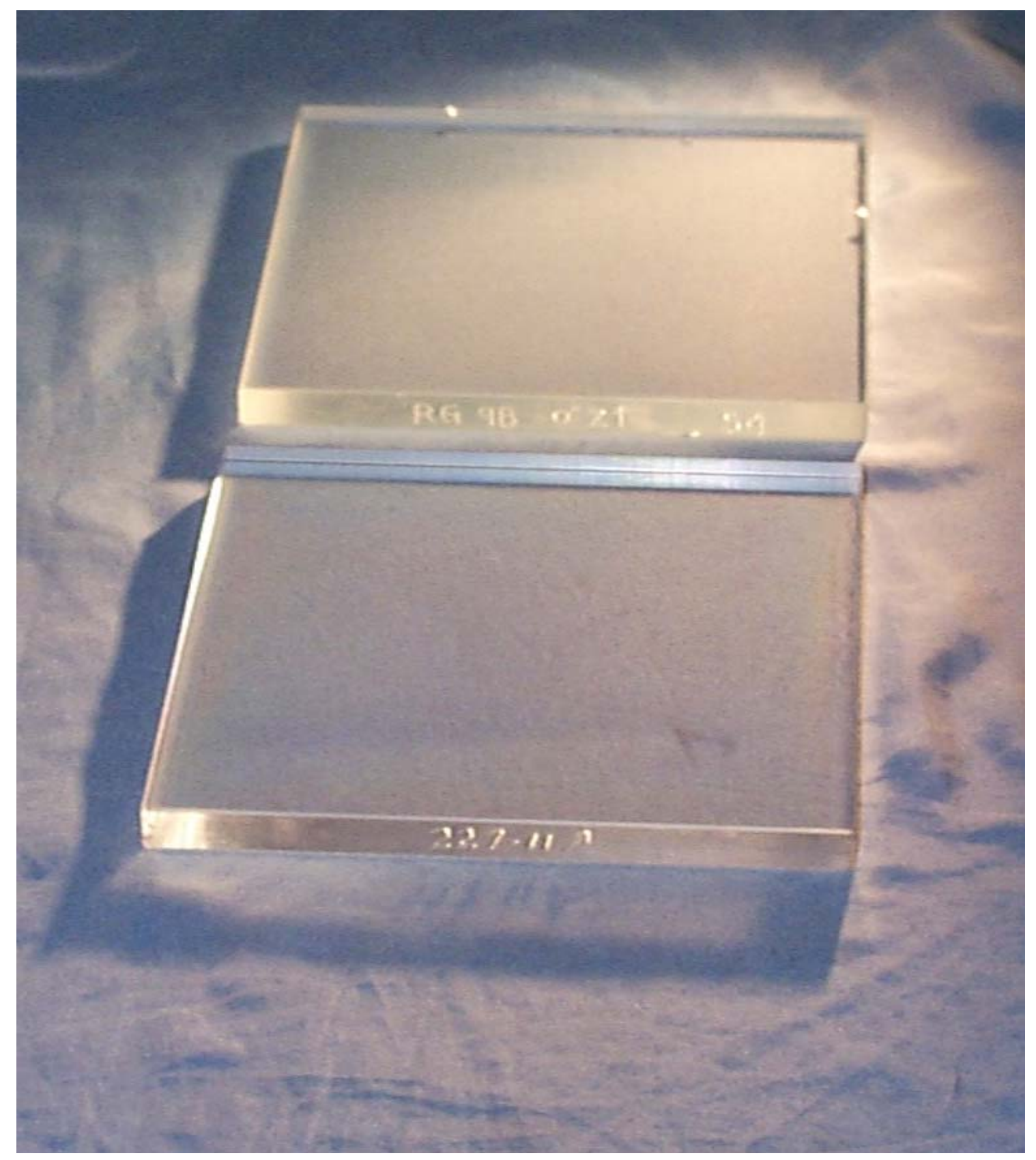

Fig. 5. Switch crystal RG9B $0^{\circ} Z$ (top) and tripler crystal 227-11. Each crystal is a $150 \mathrm{~mm}$ square sample, $10 \mathrm{~mm}$ thick.

Figs. 6 and 7 show the results for switch crystal RG9B $0^{\circ} Z$ and tripler crystal 22711 , respectively. 


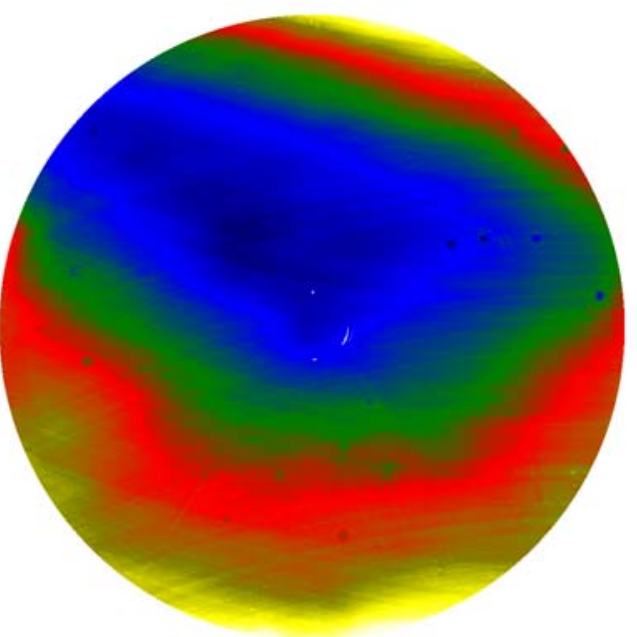

$-150 \mathrm{~nm}$

$150 \mathrm{~nm}$

$\Delta \mathbf{t}$

\section{Horizontal polarization}

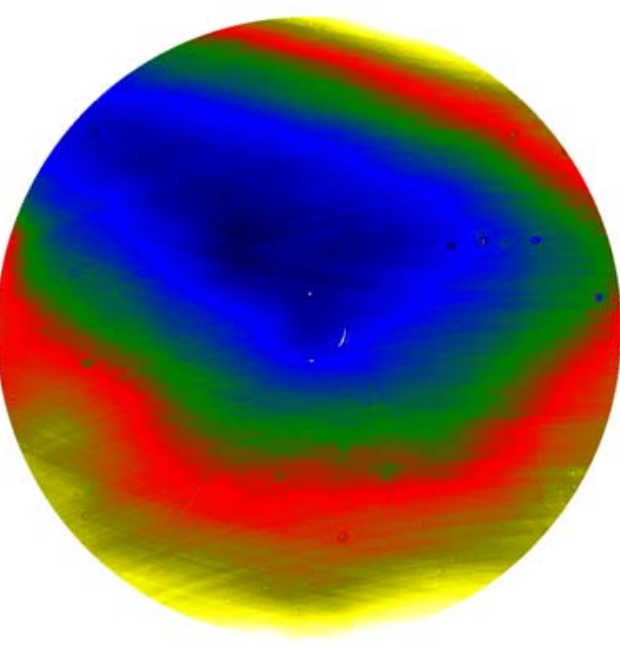

$-150 \mathrm{~nm}$

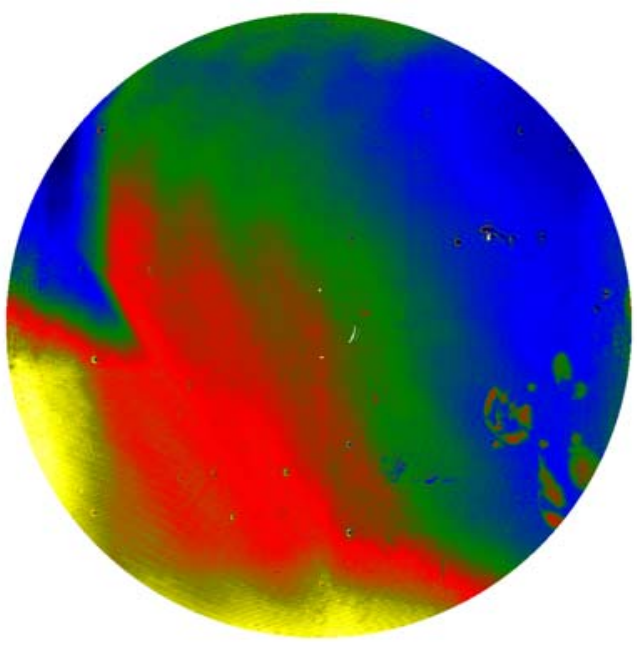

$-5 e-6$

$5 e-6$

$\Delta \mathbf{n}$

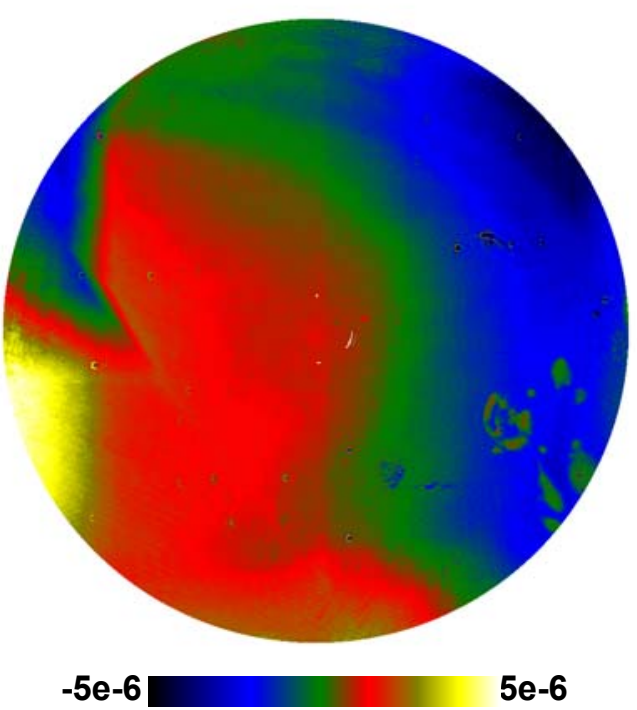

$\Delta \mathbf{t}$

Vertical polarization

Fig. 6. Measurement results for switch crystal RG9B $0^{\circ} Z$ over a $130 \mathrm{~mm}$ diameter aperture. 


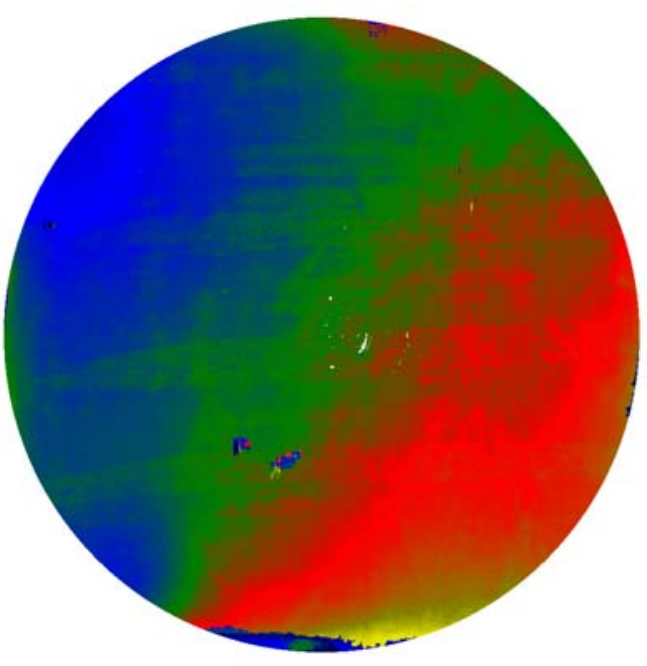

$-400 \mathrm{~nm}$

$400 \mathrm{~nm}$

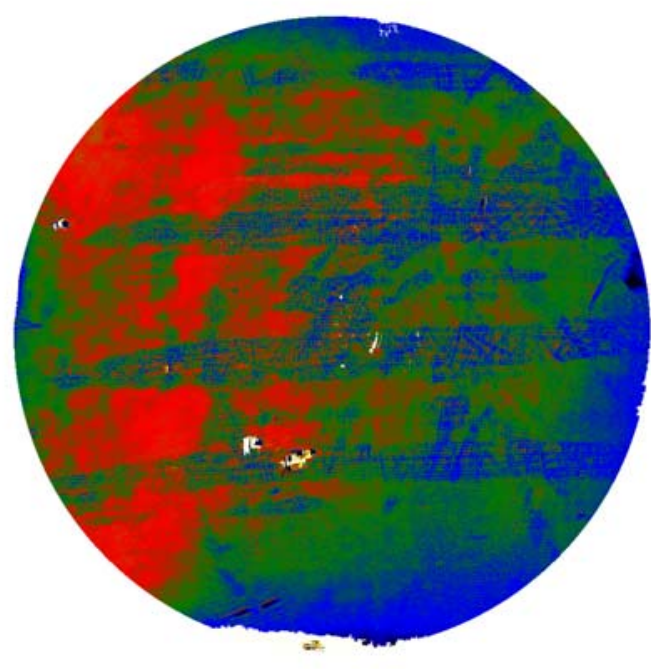

$-2 e-5$

$2 e-5$

$\Delta \mathbf{t}$

Horizontal polarization

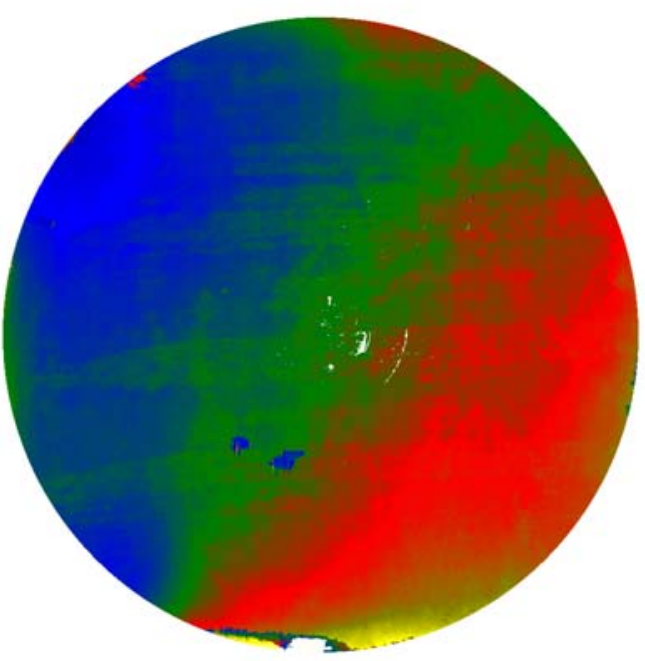

$-400 n m$

400nm

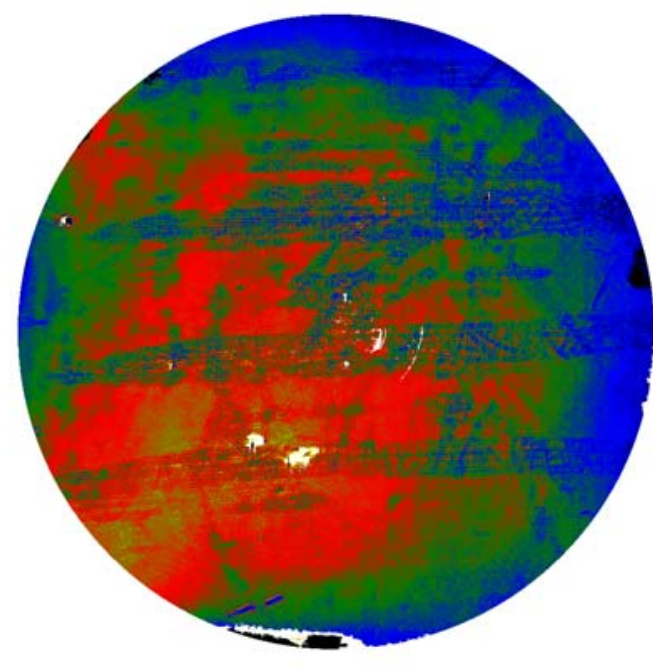

$-2 e-5$

$2 e-5$

$\Delta t$

$\Delta \mathbf{n}$

Vertical polarization

Fig. 7. Measurement results for tripler crystal $227-11$ over a $130 \mathrm{~mm}$ diameter aperture. 
There are two general observations that can be made: diamond turning marks are evident in $\Delta \mathbf{t}$ plots while $\Delta \mathbf{n}$ plots show indications of possible crystal boundary dislocations. To make a true comparison between $\Delta \mathbf{t}$ and $\Delta \mathbf{n}$ plots, both must be compared with the same metric - in this case OPD. This is done by multiplying $\Delta t$ by the nominal index $n_{0}$ and $\Delta n$ by the nominal thickness $t_{0}$ and comparing $\mathbf{n}_{0} \Delta t$ to $t_{0} \Delta n$, the OPDs introduced by each effect after a single pass through the crystal. Fig. 8 shows a sampled region $(25 \times 28 \mathrm{~mm})$ of crystal RG9B $0^{\circ} \mathrm{Z}$ for horizontal polarization. Note that diamond turning marks in $\mathbf{n}_{\mathbf{0}} \Delta \mathbf{t}$ are not present in $\mathbf{t}_{0} \Delta \mathbf{n}$, as one would expect. Likewise, sharp index steps are obvious in $\mathbf{t}_{\mathbf{0}} \Delta \mathbf{n}$ but not in $\mathbf{n}_{\mathbf{0}} \Delta \mathbf{t}$.

$\mathbf{n}_{0} \Delta t$

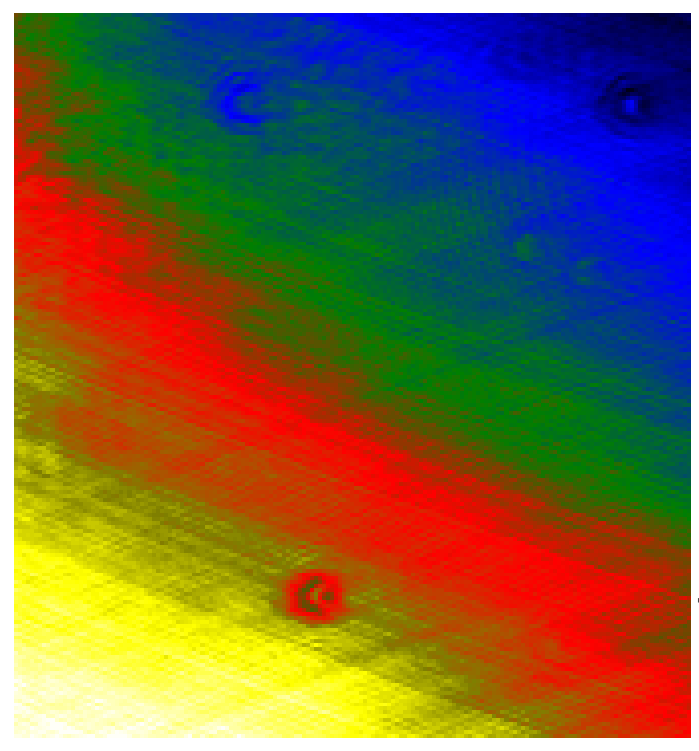

Cross-hatch diamond turning tool marks over surface $\mathbf{t}_{0} \Delta \mathbf{n}$

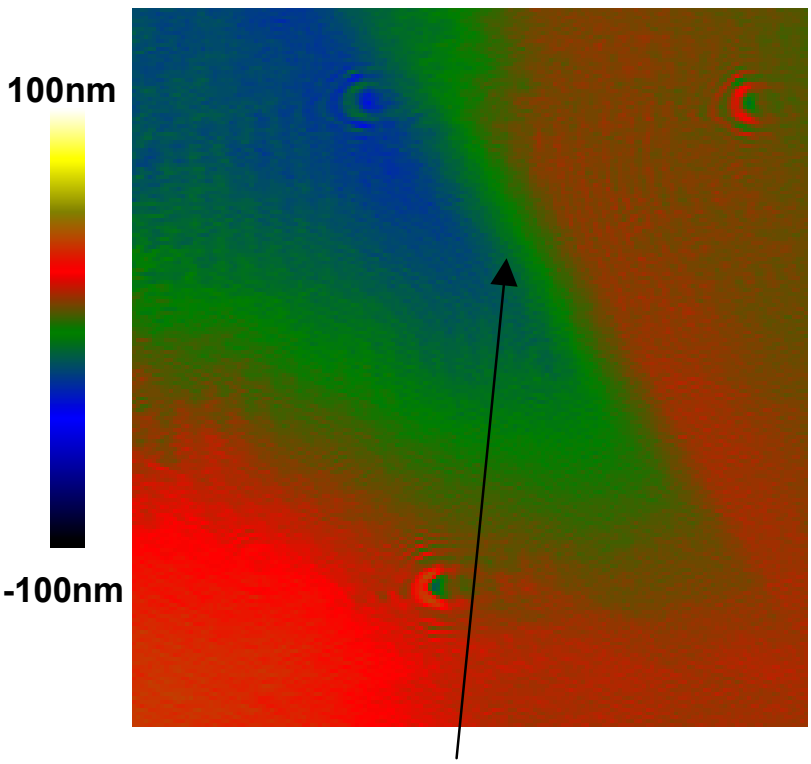

Crystal boundary dislocation

Fig. 8. Comparison of the equivalent OPD variation due to $\Delta \mathrm{t}$ and $\Delta \mathrm{n}$ for a sampled region $(25 \times 28 \mathrm{~mm})$ of crystal $R G 9 B \quad 0^{\circ} Z$ for horizontal polarization. 


\section{Comments}

This report described and demonstrated an interferometric method to determine the spatial variation in thickness and refractive index of thin NIF crystals. The method is particularly attractive because it eliminates the problem of multiple beam interference by the use of a short coherence length laser and a variable optical delay line. The spatial variation in thickness and refractive index can be determined from three measurements - interference between different pairs of reflected beams from the transmission flat, reflection flat and the two surfaces of the crystal. Furthermore, this can be done without adjusting or otherwise disturbing the interferometer, and is independent of the quality of the transmission and reflection flats.

The purpose of the two sample measurements was to demonstrate this new data acquisition technique and to show how the analysis can separate refractive index variations from thickness variations. These measurements were by no means exhaustive, nor meant to be. Multiple sets of data were not taken and compared for stability and repeatability. This was only a proof-of-principle demonstration.

Question: Is there interest in developing and using this metrology for full size NIF crystal characterization during the finishing process and/or for final certification at LLNL?

\section{References}

1. P.J. de Groot, "Measurement of Transparent Plates with Wavelength-Tuned Phase-Shifting Interferometry," Appl. Opt. 39, 2658-2663 (2000).

2. Sommargren, G.E., "Phase shifting diffraction interferometry for measuring extreme ultraviolet optics," OSA Trends in Optics and Photonics Vol. 4, Extreme Ultraviolet Lithography, Kubiak and Kania, eds. (Optical Society of America, Washington, DC 1996), pp. 108-112. 
University of California

Lawrence Livermore National Laboratory

Technical Information Department

Livermore, CA 94550

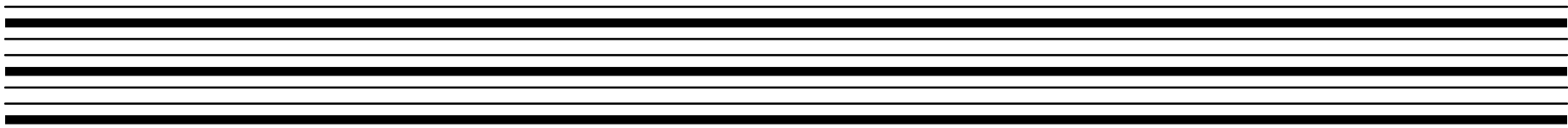

